\title{
Desinfestação superficial, germinação e regeneração in vitro a partir de sementes de calêndula
}

\author{
Superficial disinfestation, germination and regeneration in vitro from marigold seeds
}

\author{
Caroline Borges Bevilacqua ${ }^{\mathrm{I}}$ Lia Rejane Silveira Reiniger ${ }^{\mathrm{II}^{*}}$ Diego Pascoal Golle ${ }^{\mathrm{III}}$ \\ Felippe Correa da Rosa ${ }^{\text {II }}$
}

RESUMO

Os objetivos deste trabalho foram: desenvolver um protocolo de desinfestação superficial de sementes, selecionar uma metodologia de germinação in vitro, avaliar o potencial de regeneração no cultivo in vitro e a influência do tempo de cultivo no tipo de calo formado e na regeneração a partir de calos de calêndula. Para a desinfestação superficial, foram testados diferentes tempos de imersão em solução de hipoclorito de sódio a 2,5\%. Na germinação in vitro, foram testados: imersão em ácido sulfúrico absoluto; imersão em ácido clorídrico absoluto; retirada do tegumento e embebição das sementes; e embebição das sementes sem a retirada do tegumento. Para avaliar o potencial de regeneração in vitro, foram testadas diferentes concentrações de 6benzilaminopurina (BAP) e ácido alfa-naftaleno acético (ANA) e tempos de cultivo. A imersão em solução de hipoclorito de sódio a 2,5\% por 30 minutos aliada à remoção do tegumento promove a germinação in vitro de sementes de calêndula, efetuando uma desinfestação superficial satisfatória. Para a regeneração de partes aéreas e raízes a partir de sementes de calêndula não é necessária a suplementação com fitorreguladores. Na presença de BAP, independentemente da presença ou não de ANA, calos primários induzem à formação de calos esponjosos e friáveis e de calos verdes e rígidos, estes em menor número; na ausência de BAP é induzida a formação de calos pequenos. Calos jovens são mais eficientes em regenerar partes aéreas em calêndula.

Palavras-chave: Calendula officinalis L., cultura de tecidos, calogênese.

\begin{abstract}
The aims of this paper were: to develop a protocol of superficial disinfestation of marigold seeds; to select a methodology of germination in vitro of marigold seeds; to evaluate the potential regeneration of in vitro culture of marigold; and the influence of in vitro culture time in the kind of callus formed. The superficial disinfestation was perfomed by different times of immersion in $2.5 \%$ sodium hypoclorite solution. The methodology was tested by immersion in sulfuric acid; immersion in chloridric acid; removal of tegument and soaking of seeds; and just seeds soaking. To evaluate the potential of in vitro regeneration were tested different concentrations of growth regulators and culture times. The immersion in $2.5 \%$ sodium hypochlorite solutions for $30 \mathrm{~min}$ coupled with the removal of tegument promote the in vitro germination and superficial disinfestation of marigold seeds satisfactorily. Primary calli in BAP presence, with or without ANA, induce formation of spongy and friable calli and of green and hard calli, these are in least amount. Young calli are more efficient to regenerate aerial parts.
\end{abstract}

Key words: Calendula officinalis L., tissue culture, calli induction.

\section{INTRODUÇÃO}

Calendula officinalis L., espécie da família Asteraceae, é originária do Egito e subespontânea na região do Mediterrâneo, entretanto, dispersou-se

IPrograma de Pós-graduação em Ciência e Tecnologia de Sementes, Universidade Federal de Pelotas (UFPel), Pelotas, RS, Brasil.

"Departamento de Fitotecnia, Universidade Federal de Santa Maria (UFSM), 97105-900, Santa Maria, RS, Brasil. E-mail: liarejanesilveirareiniger@yahoo.com.br. *Autor para correspondência.

"IIDepartamento de Solos, UFSM, Santa Maria, RS, Brasil. 
mundialmente, sendo cultivada em todas as zonas temperadas, especialmente como planta ornamental e medicinal. A espécie é anual ou bienal e se adapta aos locais com solos férteis, úmidos e com disponibilidade de iluminação plena (SILVA, 2005).

Dentre os usos medicinais, foram relatadas ações anti-inflamatória, bactericida, antitumoral, diurética, analgésica, além de cicatrizante de feridas e erupções cutâneas (PARENTE et al., 2002). Por essas razões supracitadas, encontra-se entre as principais espécies com potencial medicinal cultivadas no Brasil (VOLPATO, 2005).

A qualidade e a uniformidade da matériaprima é um requisito fundamental a ser preenchido pelas espécies vegetais utilizadas para produzir medicamentos (RODRIGUES et al., 2004). No entanto, as plantas de calêndula caracterizam-se pela grande variabilidade, produzindo flores heterogêneas em cores e tamanhos (variando de 3 a $9 \mathrm{~cm}$ ) e de composição fitoquímica também variável, além do visível polimorfismo dos seus aquênios, em relação à forma e ao tamanho (SILVEIRA et al., 2002). Essa desuniformidade compromete tanto a qualidade quanto a padronização dessa matéria prima de fitoterápicos e cosméticos (BERTONI et al., 2006).

O cultivo in vitro de calêndula por meio da micropropagação é uma alternativa para a produção desta espécie vegetal, cuja técnica pode ser empregada para garantir a qualidade e a uniformidade das plantas produzidas, além de impedir a presença de contaminantes. Como consequência, a matéria-prima oriunda do cultivo in vitro tem características fitoquímicas padronizadas. Para tanto é necessário que ocorra a indução da proliferação celular in vitro que é estimulada, dentre outros fatores, pelo balanço hormonal, ou seja, pelo gradiente que gera um equilíbrio entre as citocininas e as auxinas, exógenas e endógenas, afetando o controle do desenvolvimento vegetal (NOGUEIRA et al., 2007).

Diante da importância da espécie, constituíram os objetivos deste trabalho: a) desenvolver um protocolo de desinfestação superficial de sementes; b) selecionar uma metodologia de germinação in vitro; c) avaliar o potencial de regeneração no cultivo in vitro e; d) avaliar a influência do tempo de cultivo no tipo de calo formado e na regeneração a partir de calos de calêndula.

\section{MATERIAL E MÉTODOS}

As sementes de Calendula officinalis analisadas são originárias da Holanda, sendo comercializadas pela empresa Isla, de Porto Alegre, Rio
Grande do Sul, em latas hermeticamente fechadas. O número do lote utilizado foi 21013-HZ, peso líquido de $50 \mathrm{~g}$, sem a presença de defensivos, o qual foi analisado em 09/2006 com validade até 09/2008, tendo $92 \%$ de germinação e 99,2\% de pureza, de acordo com as informações contidas no recipiente. Após a abertura da lata, as sementes foram mantidas em câmara seca e fria a aproximadamente $10-12^{\circ} \mathrm{C}$ e umidade relativa do ar de $35-40 \%$ durante a realização dos experimentos, que se estendeu de agosto de 2007 a agosto de 2008 .

$\mathrm{O}$ cultivo in vitro foi realizado em sala de crescimento sob temperatura de $25 \pm 3^{\circ} \mathrm{C}$, fotoperíodo de $16 \mathrm{~h}$, intensidade luminosa de $20 \mathrm{mmol} \mathrm{m}^{-2} \mathrm{~s}^{-1}$ obtida por lâmpadas fluorescentes brancas frias tipo luz do dia. O meio nutritivo básico utilizado foi o MS (MURASHIGE \& SKOOG, 1962) reduzido a $1 / 4$ da concentração de sais, contendo $15 \mathrm{~g} \mathrm{~L}^{-1}$ de sacarose e $7 \mathrm{~g} \mathrm{~L}^{-1}$ de ágar, distribuído em frascos de vidro de $150 \mathrm{ml}$ contendo $30 \mathrm{ml}$ de meio nutritivo, os quais foram previamente esterilizados em autoclave por $15 \mathrm{~min}$ a $121^{\circ} \mathrm{Cea} 1,5 \mathrm{~atm}$.

A desinfestação superficial foi iniciada pela imersão das sementes em solução de etanol a $70 \%$ (v/ v), por 30 segundos. Em seguida foram efetuados os tratamentos que consistiram de diferentes tempos $(0$, 10, 20 ou 30 minutos) de imersão em solução de hipoclorito de sódio a 2,5\% (v/v), obtida pela diluição de uma solução a $10 \%$, acrescida de uma gota de detergente comercial, seguida de três enxágues das sementes em água destilada e esterilizada em autoclave. $\mathrm{Na}$ sequência foi efetuada a remoção do tegumento das sementes sob condições assépticas. Após 15 dias de cultivo in vitro, foram avaliadas as variáveis: contaminação (fúngica e bacteriana) e germinação, expressas em porcentagem. $\mathrm{O}$ delineamento utilizado foi o inteiramente casualizado, com cinco repetições, cada uma composta por cinco frascos, contendo três sementes.

No ensaio visando à germinação in vitro de calêndula, efetuou-se, primeiramente, a desinfestação pela imersão das sementes em solução de etanol a 70\% (v/v) por 30 segundos, sucedida pela imersão em solução de hipoclorito de sódio a 2,5\% (v/v) durante 30 minutos, na qual foi adicionada uma gota de detergente comercial. Após foram realizados três enxágues das sementes em água destilada e esterilizada em autoclave. Na sequência foram testados os tratamentos que consistiram de: a) imersão em ácido sulfúrico absoluto durante 5 minutos; b) imersão em ácido clorídrico absoluto durante 5 minutos; c) retirada do tegumento e embebição das sementes em água destilada durante $12 \mathrm{~h}$; d) embebição das sementes em água destilada durante $12 \mathrm{~h}$ e; e) controle, em que as 
sementes não foram submetidas a nenhum tratamento. Após sete dias de cultivo in vitro, foi avaliada a porcentagem de germinação in vitro, cujo delineamento utilizado foi o inteiramente casualizado, com cinco repetições, cada uma composta por cinco frascos, contendo três sementes.

$\mathrm{O}$ ensaio de regeneração in vitro foi conduzido em delineamento inteiramente casualizado, utilizando-se esquema bifatorial $7 \times 2$, referente às concentrações de $\operatorname{BAP}(0 ; 2 ; 3 ; 4 ; 5 ; 6$ e $7 \mu \mathrm{M})$ e de ANA $(0$ e $0,5 \mu \mathrm{M})$, contendo cinco repetições por tratamento, cada uma composta de um frasco contendo $30 \mathrm{ml}$ de meio nutritivo e três sementes. A inoculação in vitro das sementes de calêndula foi realizada após a desinfestação superficial, na qual foi empregada imersão em solução de etanol a 70\%, por 30 segundos e, logo em seguida, imersão em solução de hipoclorito de sódio a 2,5\% por 30 minutos, acrescida de uma gota de detergente e, posteriormente, sucedida por três enxágues com água destilada e esterilizada em autoclave. Ao final de 30 dias, foram avaliadas a formação de raiz e de parte aérea, cujos resultados foram expressos em porcentagem.

No ensaio de regeneração de calos, aqueles formados em segmentos foliares de calêndula, cultivados em diferentes tempos (especificados a seguir), em meio nutritivo $1 / 4 \mathrm{MS}$ contendo diferentes concentrações de fitorreguladores, foram, posteriormente, inoculados em meio de cultura fresco de mesma composição, porém na ausência de fitorreguladores, com acréscimo de $1,5 \mathrm{~g} \mathrm{~L}^{-1}$ de carvão ativado, durante 15 dias.

Após o cultivo em meio contendo carvão, foi efetuada a transferência dos explantes para meio fresco ao qual foram adicionados fitorreguladores. $\mathrm{O}$ experimento foi conduzido utilizando-se o delineamento inteiramente casualizado, em esquema bifatorial $7 \times 2$, sendo os níveis do primeiro fator referentes às concentrações de $\mathrm{BAP}(0 ; 2 ; 3 ; 4 ; 5 ; 6$ e $7 \mu \mathrm{M})$, e os níveis do segundo fator, ao tempo de cultivo dos calos (calos velhos, com aproximadamente 135 dias de formação, e calos jovens, com 30 dias). Para cada tratamento, utilizaram-se cinco repetições, cada uma composta por um frasco contendo $30 \mathrm{ml}$ de meio nutritivo e três calos.

Após 30 dias de cultivo, foram avaliadas a presença de neorganogênese (regeneração) e a influência do uso de BAP e do tempo de cultivo no tipo de calo que foi induzido. Para os diferentes tipos de calos, foram atribuídas notas de acordo com suas características (Figura 1), sendo conferida, para calos esponjosos e friáveis, a maior nota (100), seguida por calos verdes e rígidos $(66,67)$ e, por fim, por calos pequenos $(33,33)$, ou seja, estes representaram os menores calos formados, tanto em relação aos esponjosos e friáveis quanto aos verdes e rígidos. Os valores utilizados para as notas foram selecionados com base nas médias percentuais observadas.

Os resultados foram transformados para a função arco seno de $\sqrt{x+0,5 / 100}$ e submetidos à análise de variância e de regressão polinomial, para tratamentos quantitativos e comparação das médias pelo teste de Tukey em nível de 5\% de probabilidade de erro, para os tratamentos qualitativos, com o auxílio do pacote estatístico SANEST (ZONTA \& MACHADO, 1987).

\section{RESULTADOS E DISCUSSÃO}

Em relação à contaminação fúngica, foi observada diferença significativa entre os tratamentos. Com o emprego de solução de hipoclorito de sódio a $2,5 \%$ e o aumento no tempo de imersão, houve redução na contaminação (Figura 2A). No tratamento controle,

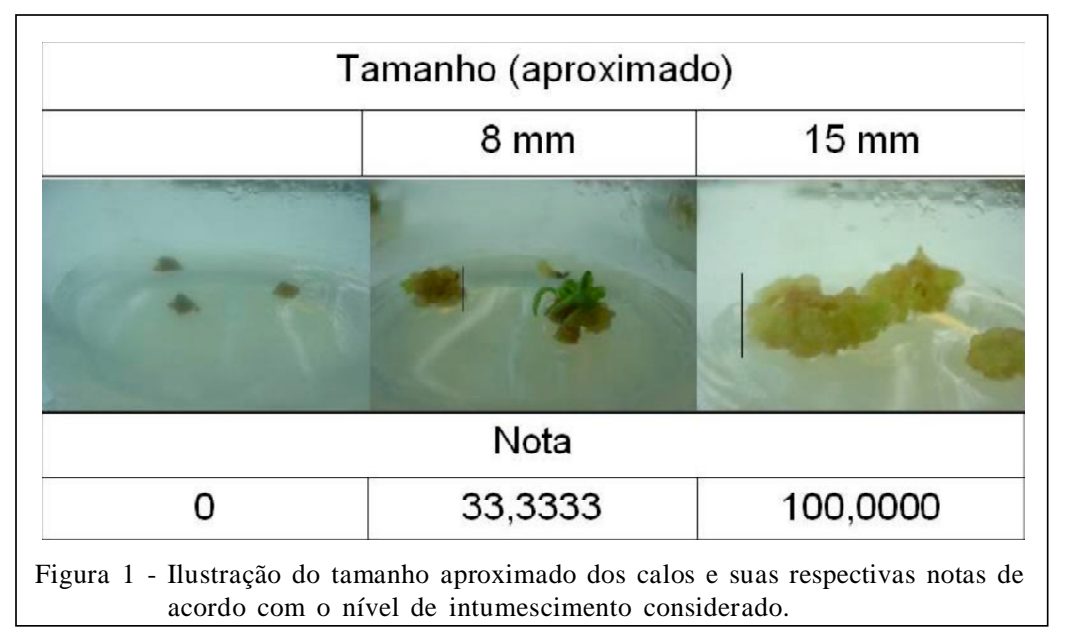

Ciência Rural, v.41, n.5, mai, 2011. 


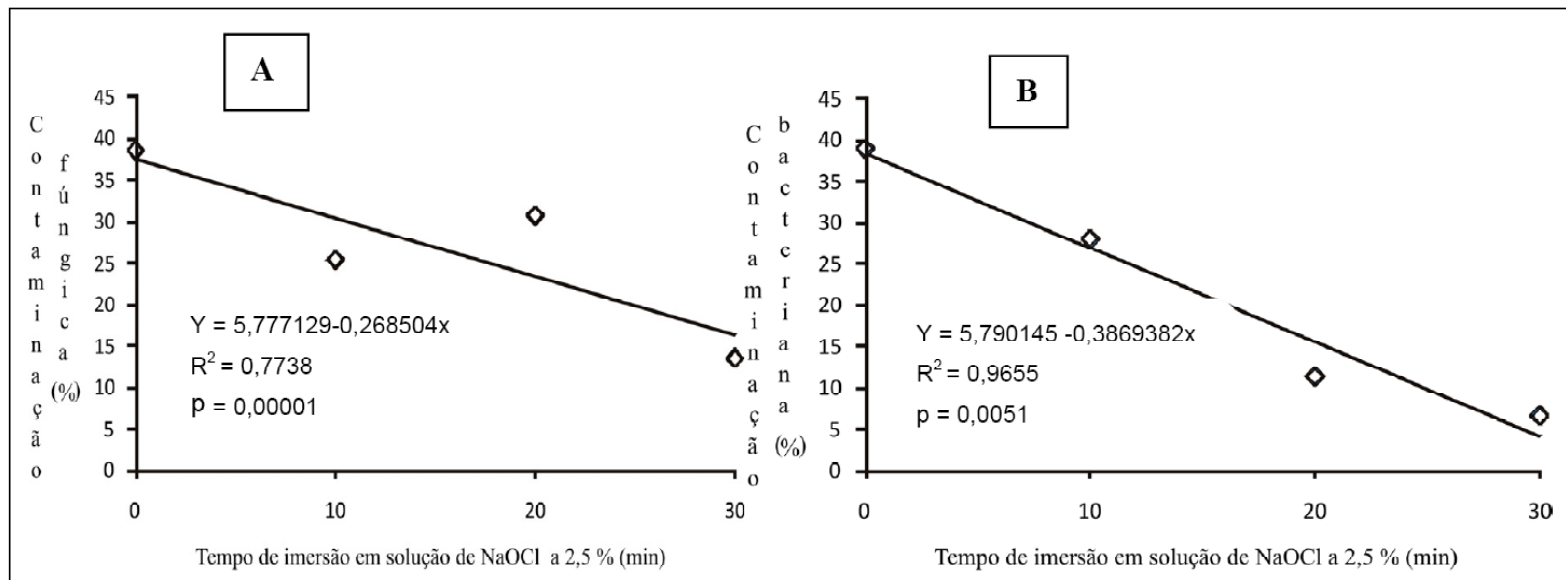

Figura 2 - Contaminação fúngica (A) e bacteriana (B) em sementes de calêndula sem tegumento, aos 15 dias de cultivo in vitro, em função de diferentes tempos de imersão em solução de hipoclorito de sódio a 2,5\%.

43,6\% das sementes continham contaminação, o que indica a necessidade de utilizar a imersão em solução de hipoclorito de sódio a $2,5 \%$ para minimizar a ocorrência de contaminantes fúngicos nas culturas in vitro de calêndula. Da mesma maneira, houve redução na contaminação bacteriana com o aumento no tempo de imersão em hipoclorito de sódio, observando-se uma média de 93,9\% de desinfestação (Figura 2B). Esse resultado ratifica a eficiência do uso desse agente desinfestante em controlar contaminações microbianas.

Em outro trabalho realizado com sementes de calêndula como explantes, ocorreu desinfestação de apenas 64\% (BERTONI et al., 2006). A germinação in vitro de porongo (Lagenaria siceraria (Mol.) Standl) também foi otimizada através da remoção do tegumento das sementes e da desinfestação empregando solução de hipoclorito de sódio a 3-4\% por 10 minutos (BISOGNIN et al., 2008). Em alecrimpimenta (Lippia sidoides Cham), o uso de $0,8 \%$ de hipoclorito de sódio com um tempo de imersão de 16 minutos promoveu uma melhor desinfestação dos segmentos nodais (COSTA et al., 2007).

A germinação in vitro foi superior com a retirada do tegumento das sementes, obtendo-se $74 \%$ de plântulas de calêndula (Tabela 1). Os demais tratamentos, incluindo o controle, produziram um percentual muito reduzido ou nenhuma germinação, não diferindo entre si. O tegumento das sementes de calêndula, aparentemente, não foi rompido pela água ou pelos ácidos empregados, impedindo a germinação. Também é possível que os tempos de imersão em ácido tenham sido insuficientes.

De maneira semelhante, em outro estudo com calêndula, a excisão de embriões maduros de sementes foi eficiente em promover a germinação in vitro (GRZELAK \& JANISZOWA, 2002). Em Passiflora giberti N.E. Brown, a retirada parcial do tegumento elevou o percentual de sementes germinadas in vitro (VIANA \& JUNGHANS, 2006).

No ensaio visando à regeneração in vitro a partir de sementes de calêndula, todos os explantes que germinaram tinham parte aérea, independente do tratamento aplicado, sendo que, após 15 dias de cultivo in vitro, ocorreram rizogênese e calogênese. $\mathrm{O}$ tratamento que promoveu maior rizogênese foi aquele que não utilizou BAP, obtendo-se uma média de $53,92 \%$. Para que ocorresse a rizogênese in vitro, não foi necessária a suplementação com ANA, tendo sido observado $19,75 \%$ de formação de raiz na presença deste regulador de crescimento e $33,85 \%$, na sua ausência.

Além disso, foram observadas brotações em cluster, para as quais havia a possibilidade de regenerar aproximadamente 20 plantas por brotação. Dessa maneira foram observadas a organogênese direta de folhas e a organogênese indireta. A partir dos calos

Tabela 1 - Germinação in vitro (\%) em sementes de calêndula utilizando-se diferentes tratamentos.

\begin{tabular}{lc}
\hline Tratamento & Média de germinação (\%) \\
\hline Sem tegumento e com embebição & $74,41 \mathrm{a}$ \\
Embebição & $3,94 \mathrm{~b}$ \\
Imersão em ácido sulfúrico & $2,61 \mathrm{~b}$ \\
Imersão em ácido clorídrico & $0,00 \mathrm{~b}$ \\
Controle & $0,00 \mathrm{~b}$ \\
\hline
\end{tabular}

* Médias seguidas por letras distintas diferem entre si pelo Teste de Tukey em nível de 5\% de probabilidade de erro. 
formados, ocorreu neorganogênese de ápices vegetativos, com o desenvolvimento de novas folhas.

Em abacaxizeiro (Ananas comosus (L.) Merr.), a melhor taxa de brotos axilares por explante foi de 16, sendo verificada no tratamento que continha ANA $(2,7 \mu \mathrm{M})+\mathrm{BAP}(4,4 \mu \mathrm{M})($ GUERRA et al., 1999). Também com abacaxizeiro, a adição de $1 \mathrm{mg} \mathrm{L}^{-1}$ de BAP e $0,5 \mathrm{mg}$ $\mathrm{L}^{-1}$ de ANA ao meio de cultivo resultou na maior regeneração de brotos e na maior produção de matéria fresca, apesar das dificuldades de individualização desses brotos (MACÊDO et al., 2003).

A ocorrência de interações entre o tempo de cultivo de calos e as concentrações de BAP foi observada (Tabela 2), as quais interferiram no tipo de calo originado, sendo observada a presença de calos pequenos, esponjosos e friáveis, além de calos verdes e rígidos.

$\mathrm{Na}$ ausência de BAP, formaram-se calos pequenos, tanto naqueles jovens quantos nos velhos, sendo que, com a adição desta citocinina, formaram-se calos esponjosos e friáveis, independentemente do tempo de cultivo dos calos primários, exceto a $6 \mu \mathrm{M}$, em que calos jovens originaram calos verdes e rígidos. Dessa forma observa-se que a suplementação de BAP no meio nutritivo, provavelmente, alterou o balanço hormonal endógeno das culturas, favorecendo o crescimento dos calos secundários.

A formação tanto de calos verdes quanto pequenos foi descrita por GRZELAK \& JANISZOWSKA (2002), os quais foram os primeiros pesquisadores a induzir a formação de calos em calêndula, em culturas em suspensão de células de segmentos foliares e cotilédones utilizados como explantes.

No presente estudo, ocorreu a regeneração de partes aéreas em $10 \%$ dos calos, sendo $2 \%$ oriundos

Tabela 2 - Médias das notas atribuídas aos tipos de calos formados a partir de calos jovens e velhos em diferentes concentrações de BAP.

\begin{tabular}{cll}
\hline Concentrações de BAP $(\mu \mathrm{M})$ & Calos jovens & Calos velhos \\
\hline 0 & $33,3^{*} \mathrm{bB} * *$ & $33,3 \mathrm{bA}$ \\
2 & $72,9 \mathrm{aB}$ & $100 \mathrm{aA}$ \\
5 & $79,5 \mathrm{aB}$ & $100 \mathrm{aA}$ \\
6 & $66,6 \mathrm{aB}$ & $100 \mathrm{aA}$ \\
7 & $72,9 \mathrm{aB}$ & $100 \mathrm{aA}$ \\
\hline
\end{tabular}

*Notas atribuídas aos calos: $<33,33=$ calo pequeno; 33,34-66,67 = calo verde e rígido; $\mathrm{e} \geq 66,68$ = calo esponjoso e friável.

**Médias seguidas de letras minúsculas distintas diferem na coluna e médias seguidas de letras maiúsculas distintas diferem na linha pelo Teste de Tukey em nível de 5\% de probabilidade de erro. de calos velhos, e o restante, de calos jovens. Isso sugere que calos cultivados durante 75 dias são mais indicados para a regeneração em calêndula se comparados a calos com 180 dias em cultivo, pois é possível que os calos cultivados por mais tempo tenham perdido seu potencial morfogênico. Em tomateiro (Lycopersicon esculentum CV. IPA5), após 150 dias de cultivo, $0,27 \%$ dos calos regeneraram, sendo esses calos obtidos através da cultura in vitro de anteras (BRASILEIRO et al., 1999).

\section{CONCLUSÃO}

A imersão em solução de hipoclorito de sódio a $2,5 \%$ por 30 minutos mais a remoção do tegumento promovem a germinação in vitro de sementes de calêndula. Para a regeneração de partes aéreas e raízes a partir de sementes de calêndula, nãoé necessária a suplementação com fitorreguladores; na presença de BAP, independentemente da presença ou não de ANA, calos primários induzem à formação de calos esponjosos e friáveis e de calos verdes e rígidos. Calos jovens são mais eficientes em regenerar partes aéreas em calêndula.

\section{REFERÊNCIAS}

BERTONI, B.W. et al. Micropropagação de Calendula officinalis L. Revista Brasileira de Plantas Medicinais, v.8, n.2, p.48-54, 2006.

BRASILEIRO, A.C.R. et al. Callus induction and plant regeneration of tomato (Lycopersicon esculentum CV. IPA5) via anther culture. Ciência Rural, v.29, n.4, p.619-623, 1999. Disponível em: <http://dx.doi.org/doi: 10.1590/S010384781999000400008>. Acesso em:17 fev. 2011. doi: 10.1590/ S0103-84781999000400008.

BISOGNIN, D.A. et al. Germinação e propagação in vitro de porongo. Ciência Rural, v.38, n.2, p.332-339, 2008. Disponível em: <http://dx.doi.org/doi:10.1590/S010384782008000200006>. Acesso em:17 fev. 2011. doi: 10.1590/ S0103-84782008000200006.

COSTA, A.S. et al. Estabelecimento de alecrim-pimenta in vitro. Horticultura Brasileira, v.25, n.1, p.68-72, 2007. Disponível em: <http://dx.doi.org/doi:10.1590/S010205362007000100013>. Acesso em:17 fev. 2011. doi: 10.1590/ S0102-05362007000100013.

GUERRA, M.P. et al. Estabelecimento de um protocolo regenerativo para a micropropagação do abacaxizeiro. Pesquisa Agropecuária Brasileira, v.34, n.9, p.1557-1563, 1999.

GRZELAK, A.; JANISZOWSKA, W. Initiation and growth characteristics of suspension cultures of Calendula officinalis cells. Plant Cell, Tissue and Organ Culture, v.71, n.1, p.29-40, 2002. Disponível em: <http://dx.doi.org/doi:10.1023/ A:1016553909002>. Acesso em: 17 fev. 2011. doi: 10.1023/ A:1016553909002. 
MACÊDO, C.E.C. et al. Concentrações de ANA e BAP na micropropagação de abacaxizeiro L. Merril (Ananas comosus) e no cultivo hidropônico das plântulas obtidas in vitro. Revista Brasileira de Fruticultura, v.25, n.3, p.501-504, 2003. Disponível em: <http://dx.doi.org/doi: 10.1590/S010029452003000300035>. Acesso em:17 fev. 2011. doi: 10.1590/ S0100-29452003000300035.

MURASHIGE, T.; SKOOG, F. A revised medium for rapid growth and bioassays with tobacco tissue culture. Physiologia Plantarum, v.15, n.1, p.473-497, 1962. Disponível em: 〈http://dx.doi.org/doi:10.1111/j.1399-3054.1962.tb08052.x〉. Acesso em:17 fev. 2011. doi: 10.1111/j.13993054.1962.tb08052.x.

NOGUEIRA, R.C. et al. Indução de calos em explantes foliares de murici-pequeno (Byrsonima intermedia A. Juss.). Ciência e Agrotecnologia, v.31, n.2, p.366-370, 2007. Disponível em: $\quad<$ http://dx.doi.org/doi:10.1590/S141370542007000200015>. Acesso em:17 fev. 2011. doi: 10.1590/ S1413-70542007000200015.

PARENTE, L.M.L. et al. Calendula officinalis: características, propriedades químicas e terapêuticas. Arquivos de Ciências da Saúde, v.6, n.2, p.165-169, 2002.

RODRIGUES, P.O. et al. Influência de diferentes sistemas de solventes no processo de extração de Calendula officinalis L.
(Asteraceae). Latin American Journal of Pharmacy, v.23, n. 1, p.27-31, 2004.

SILVA, F. Avaliação do teor e da composição química do óleo essencial de plantas medicinais submetidas a processos de secagem e armazenamento. 2005. $168 \mathrm{f}$. Tese (Doutorado em Engenharia Agrícola) - Universidade Estadual de Campinas, SP.

SILVEIRA, M.A.M. et al. Maturação fisiológica de sementes de calêndula (Calendula officinalis L.). Revista Brasileira de Sementes, v.24, n.2, p.31-37, 2002.

VIANA, A.J.C.; JUNGHANS, T.G. Germinação in vitro e em casa de vegetação de sementes de Passiflora giberti N.E. Brown com tegumento íntegro e parcialmente removido. In: WORKSHOP DE RECURSOS GENÉTICOS VEGETAIS NO ESTADO DA BAHIA, 2., 2006, Ilhéus, Bahia. Magistra, v.18, n. esp., p.72, 2006.

VOLPATO, A.M.M. Avaliação do potencial antibacteriano de Calendula officinalis (Asteraceae) para seu emprego como fitoterápico. 2005. 137f. Tese (Doutorado em Ciências) - Universidade Federal do Paraná, Curitiba, PR.

ZONTA, E.P.; MACHADO, A.A. SANEST - Sistema de análise estatística para microcomputadores. Pelotas: DMEC/IFM/UFPel, 1987. 138p. 